\title{
Chlorine Resistant Membrane and The Mechanism of Membrane Degradation by Chlorine
}

\author{
Ja-young Koo ${ }^{1}$, Jong Hwa Lee ${ }^{2}$, Yong Doo Jung², Sung Pyo Hong ${ }^{2}$ and Sung Ro Yoon ${ }^{2}$ \\ ${ }^{1}$ Woongjin Chemical Inc., 28 Alpine Street, Billerica, MA 01862, USA. \\ ${ }^{2}$ Woongjin Chemical Inc., 287 Gongdan-Dong, Gumi, Kyungbuk, Korea. \\ *To whom correspondence should be addressed. Email:jayoung_koo@comcast.net.
}

\begin{abstract}
Polyamide reverse osmosis membrane used successfully for water desalination is made from the interfacial reaction of meta-phenylenediamine (MPD) with trimesoyl chloride. One problem with the membrane is that its performance is deteriorated upon prolonged exposure to chlorine often used for disinfecting feed water. ATR-FTIR and XPS analysis show chlorine reacts with the amide hydrogen and is attached to the polyamide membrane. A chlorine resistant membrane has been made using a non-MPD amine and appears to be five times as chlorine-resistant as the MPD-based membrane. ATR-FTIR and XPS analysis also show the chlorine-resistant membrane picks up chlorine much less than the MPD-based membrane upon exposure to chlorine. Monochloramine does not appear to affect adversely polyamide membranes.
\end{abstract}

\section{KEYWORDS}

Polyamide, reverse osmosis, membrane, chlorine degradation, chlorine-resistant, monochloarmine

\section{INTRODUCTION}

Polyamide reverse osmosis membranes have been used successfully for seawater desalination, purifying brackish water and recycling waste water. During the process, the membranes are often exposed to chlorine in feed water due to malfunction of dosing equipment of sodium bisulfite reducing chlorine to harmless chloride anion. Chlorine attacks the polyamide membranes to cause membrane failure as measured by enhanced passage of both salt and water. In this respect, a chlorine-resistant membrane is highly desirable not only for an accidental exposure to chlorine, but also long term exposure to chlorine in the feed water to inhibit microbial activities on the membrane.

It is well known that meta-phenylenediamine (MPD) moiety of the commercial polyamide membrane made from the interfacial reaction of MPD and trimesoyl chloride is the site of chlorine attack, suggesting that MPD with electron withdrawing group or non-MPD diamines may give more chlorine-resistant polyamide membranes (Kawaguchi, 1984). Accordingly, a new chlorine-resistant polyamide membrane (CRM) has been manufactured using a non- 
MPD diamine. Chlorine resistance test on the commercial polyamide membrane and the CRM has been carried out using sodium hypochlorite and chloramines, respectively. It has been reported that commercial polyamide membranes showed fairly strong resistance to chloramine in the absence of ferric or aluminum ion, but they did not last long in the presence of both chloramines and the metal ions (Gabelich, 2002). The damaged membranes were characterized employing XPS (X-ray photoelectron spectroscopy) and ATR-FTIR.

\section{METHODOLOGY}

\section{Materials}

BE, a brackish water reverse osmosis membrane, manufactured by Woongjin Chemical Inc. (formerly Saehan Industries Inc) was used for chlorine resistance test. The chlorine resistant membrane (CRM) was made using a proprietary diamine and trimesoyl chloride (TMC), which was purchased from Aldrich Chemical, following the previously known procedure (Cadotte, 1981). Sodium hypochlorite as $12 \%$ aqueous solution was obtained from DC Chemical Co. Ltd., Seoul, Korea. Chloramine was generated in situ using sodium hypochlorite and ammonium chloride in a $4: 1$ ratio of $\mathrm{Cl}_{2}$ and $\mathrm{N}$ by weight.

Static chlorine resistance test was carried out by soaking membranes in an aqueous solution of 500 ppm sodium hypochlorite at pH 6 for 14 days. Fresh hypochlorite solution was used everyday. The salt rejection and flux of the membranes exposed to chlorine were measured using a bench scale test system in a cross-flow mode at 225 psi. The cell size is $15 \mathrm{~cm}$ in length, $10 \mathrm{~cm}$ in width and $0.25 \mathrm{~cm}$ in height.

Long term chlorine resistance test on the membranes was performed using 4"x 40" elements in a pilot system set for $15 \%$ recovery to give about 15 gfd flux for both BE and CRM from a feed water containing $10 \mathrm{ppm}$ sodium hypochlorite at $\mathrm{pH} 7$ at a pressure of $100 \mathrm{psi}$. The initial salt rejection and flux of BE and CRM were 99.1\% and 30 gfd, and 99.2\% and 27 gfd, respectively at 225 psi using $2000 \mathrm{ppm} \mathrm{NaCl}$. The feed water was city tap water of Seoul containing about $200 \mathrm{ppm}$ total dissolved solid (TDS). Aqueous solution of sodium hypochlorite was added to the feed water periodically to maintain $10 \mathrm{ppm}$ residual chlorine concentration.

The effect of chloramines on BE and CRM membranes were conducted using 1.8”x12” element in a circulating system set for $15 \%$ recovery. A feed water containing $10 \mathrm{ppm}$ chloramines and $2 \mathrm{ppm}$ ferric chloride in deionized water at $\mathrm{pH} 7$ was circulated through the elements at 225 psi. The feed water was freshly prepared every other day. 


\section{Analytical Equipment}

ATR-FTIR spectra were obtained using IlluminatIR (SensIR, Inc, CT, USA). Survey XPS (Xray photoelectron spectroscopy, Sigma Probe, ThermoVG, U.K.) spectra were obtained by scanning over 0-1000 eV electron binding energy with a resolution of $1 \mathrm{eV}$. High resolution spectra (multiflex) were obtained by averaging 100 scans for each element with a resolution of $0.1 \mathrm{eV}$ and peak deconvolution was performed to estimate the binding energy shift of each element.

\section{RESULTS}

\section{XPS Analysis}

Both CRM and BE soaked in 500 ppm sodium hypochlorite at pH 6 were analyzed using XPS and ATR-FTIR. XPS analysis of BE exposed to chlorine for one day and 14 days in Fig. 1 shows peaks due to oxygen at $530 \mathrm{eV}$, nitrogen at $400 \mathrm{eV}$ and carbon at $285 \mathrm{eV}$, and also new peaks at 200 and 270 due to chlorine atom attached to the polyamide membrane.

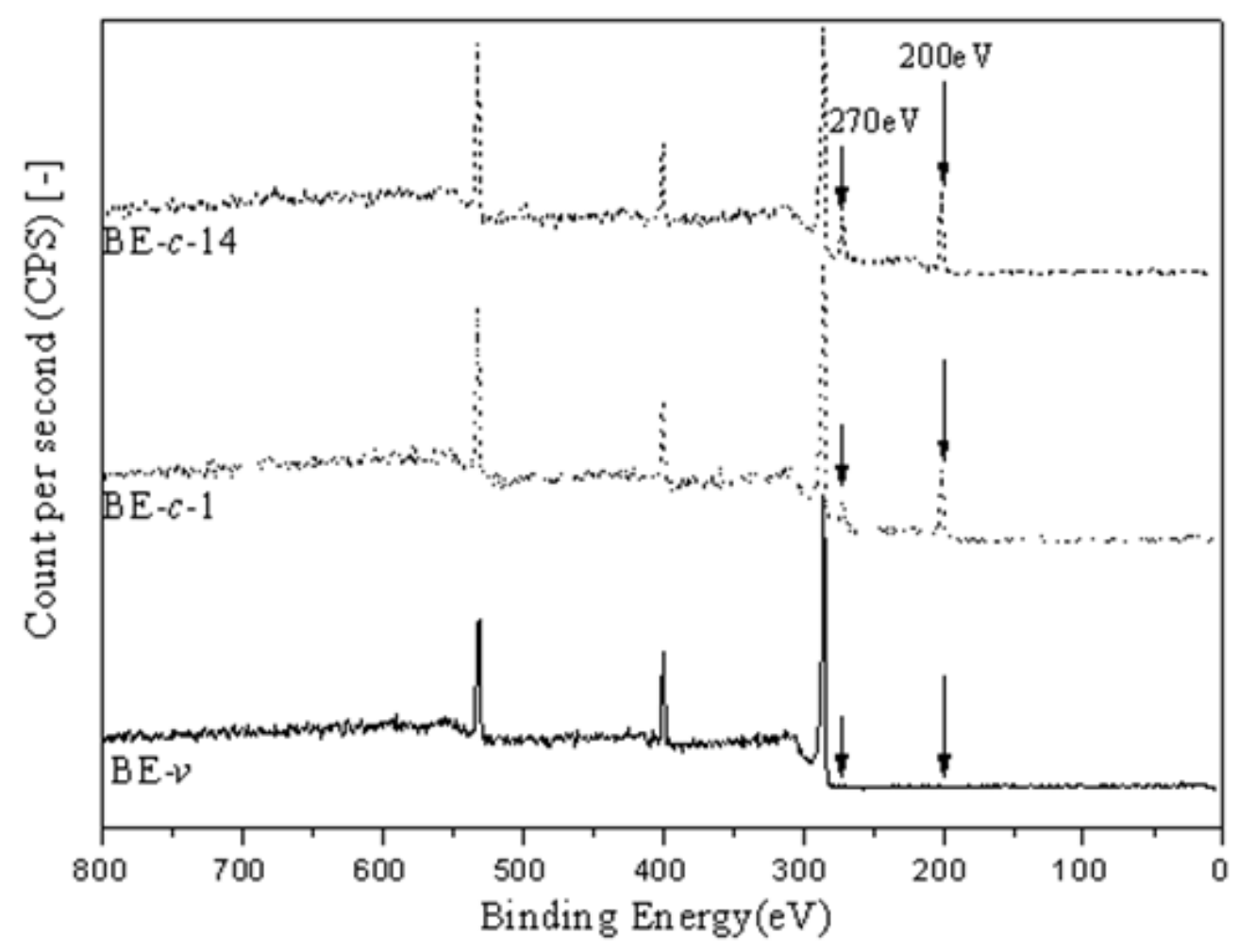

Figure 1. XPS of chlorine damaged BE (BE- $v$ and BE-c denotes virgin and chlorineexposed BE membrane, respectively). 
XPS analysis of CRM exposed to chlorine for 1 day and 14 days in Fig. 2 shows new peaks at 200 and $270 \mathrm{eV}$ assigned to chlorine atom attached to the membrane in addition to oxygen at $530 \mathrm{eV}$, nitrogen at $400 \mathrm{eV}$ and carbon at $285 \mathrm{eV}$. The new peaks in Fig. 2 are much smaller than those in Figure 1.

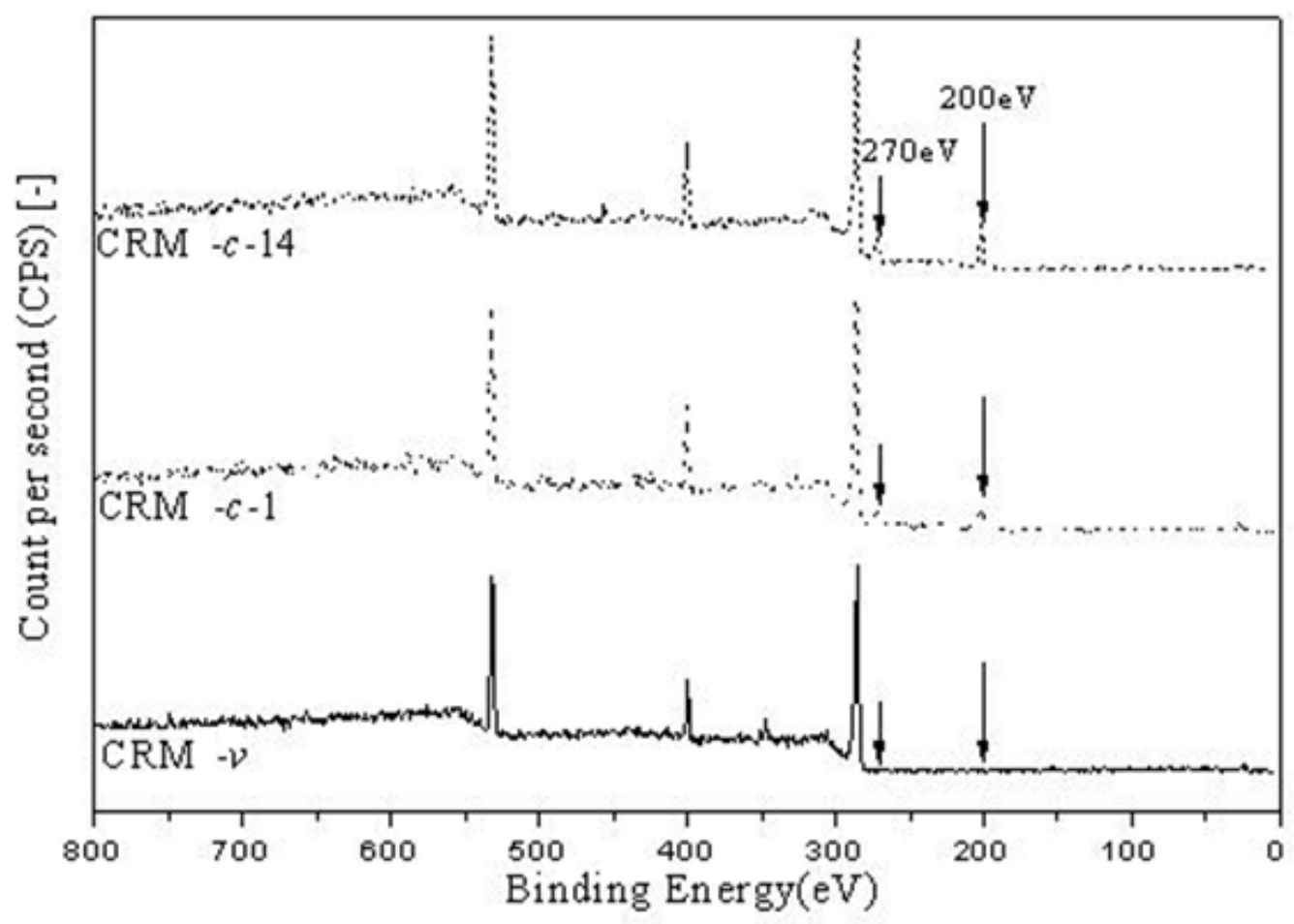

Figure 2. XPS of chlorine damaged CRM (CRM- $v$ and CRM-c denote virgin and CRM membrane exposed to chlorine, respectively).

Fig. 3 shows the atomic concentration ratio of chlorine to nitrogen $(\mathrm{Cl} / \mathrm{N})$ of $\mathrm{BE}$ and $\mathrm{CRM}$ upon exposure to chlorine as shown in Figures 1 and 2. 


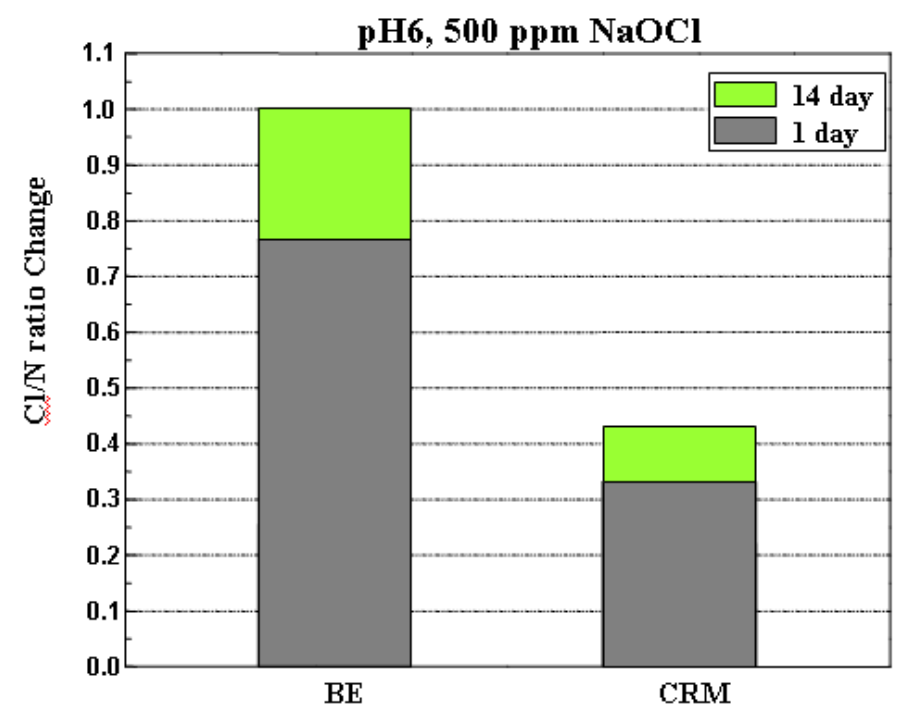

Figure 3. $\mathrm{Cl} / \mathrm{N}$ ratio of chlorine damaged $\mathrm{BE}$ and $\mathrm{CRM}$

\section{Effect of pH on Chlorination of Polyamide Membranes}

Fig. 4 exhibits the effect of $\mathrm{pH}$ on chlorination of $\mathrm{BE}$ membrane, which is exposed to 1000 ppm chlorine at $\mathrm{pH} 4$ for $10 \mathrm{~min}$. and at $\mathrm{pH} 10$ for $1200 \mathrm{~min}$. At $\mathrm{pH}$ 4, $\mathrm{BE}$ is chlorinated much faster than $\mathrm{pH} 10$.

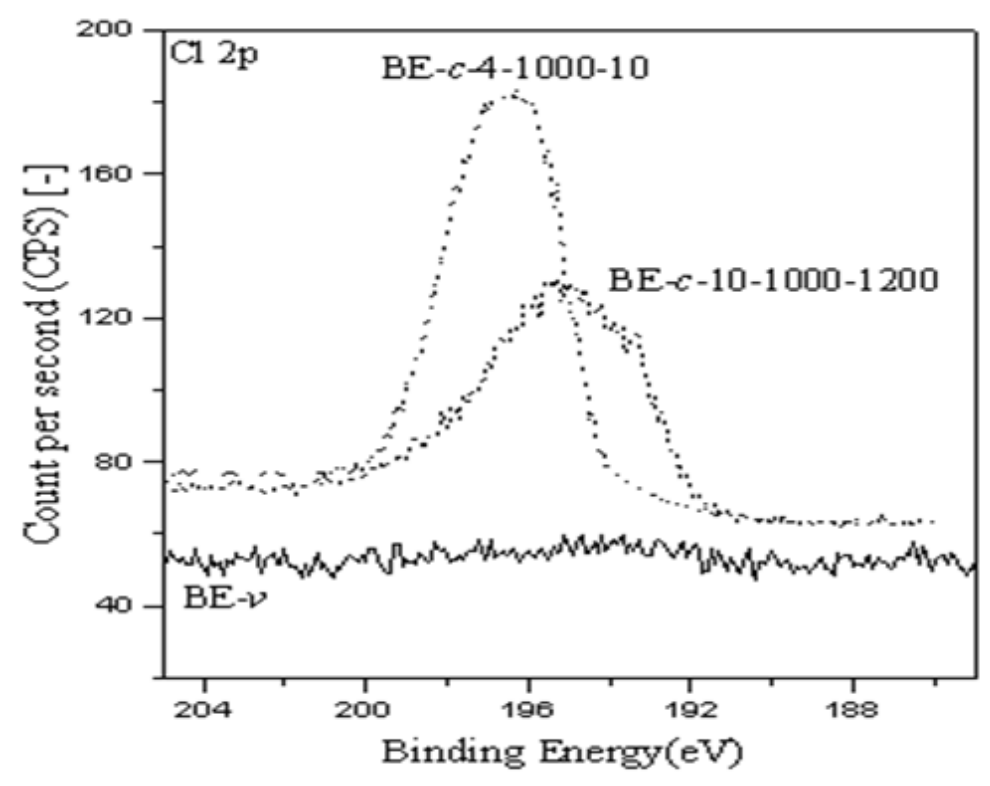

Figure 4. Effect of $\mathrm{pH}$ on the degree of chlorination of $\mathrm{BE}$ membrane. $v$ and c denote 
virgin and chlorine-exposed, respectively. The first numerals represent $\mathrm{pH}, 1000$ is the concentration of chlorine in ppm and the last numerals are exposed time in min.

\section{ATR-FTIR Analysis}

Fig. 5 shows ATR-FTIR spectra of BE membranes before and after exposure to chlorine. It is noticeable that virgin BE membrane displays a peak at $3326 \mathrm{~cm}^{-1}$ due to $\mathrm{N}-\mathrm{H}$ stretching, a peak at $1603 \mathrm{~cm}^{-1}$ due to an aromatic ring stretching and a peak at $1543 \mathrm{~cm}^{-1}$ due to in-plane $\mathrm{N}-\mathrm{H}$ bending (amide II peak) and those peaks disappeared in the case of BE exposed to chlorine.

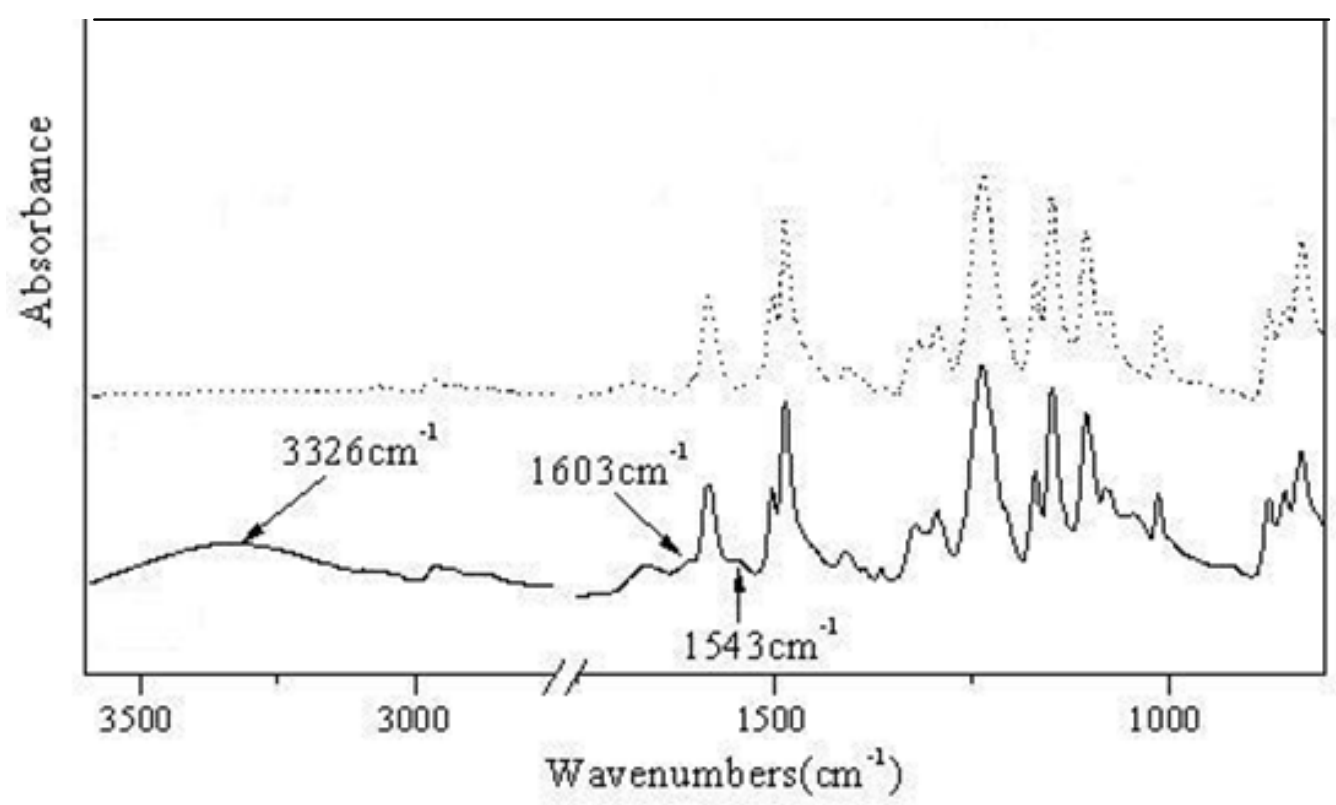

Figure 5. ATR-FTIR of virgin (lower spectrum) and chlorine damaged BE membrane (upper spectrum).

Fig. 6 exhibits ATR-FTIR spectra of CRM membranes before and after exposure to chlorine. It is noticeable that virgin CRM membrane displays a peak at $3326 \mathrm{~cm}^{-1}$ due to $\mathrm{N}-\mathrm{H}$ stretching, a peak at $1603 \mathrm{~cm}^{-1}$ due to an aromatic ring stretching and a peak at $1543 \mathrm{~cm}^{-1}$ due to in-plane N-H ending (amide II peak) and the three peaks disappeared in the case of CRM exposed to chlorine. 


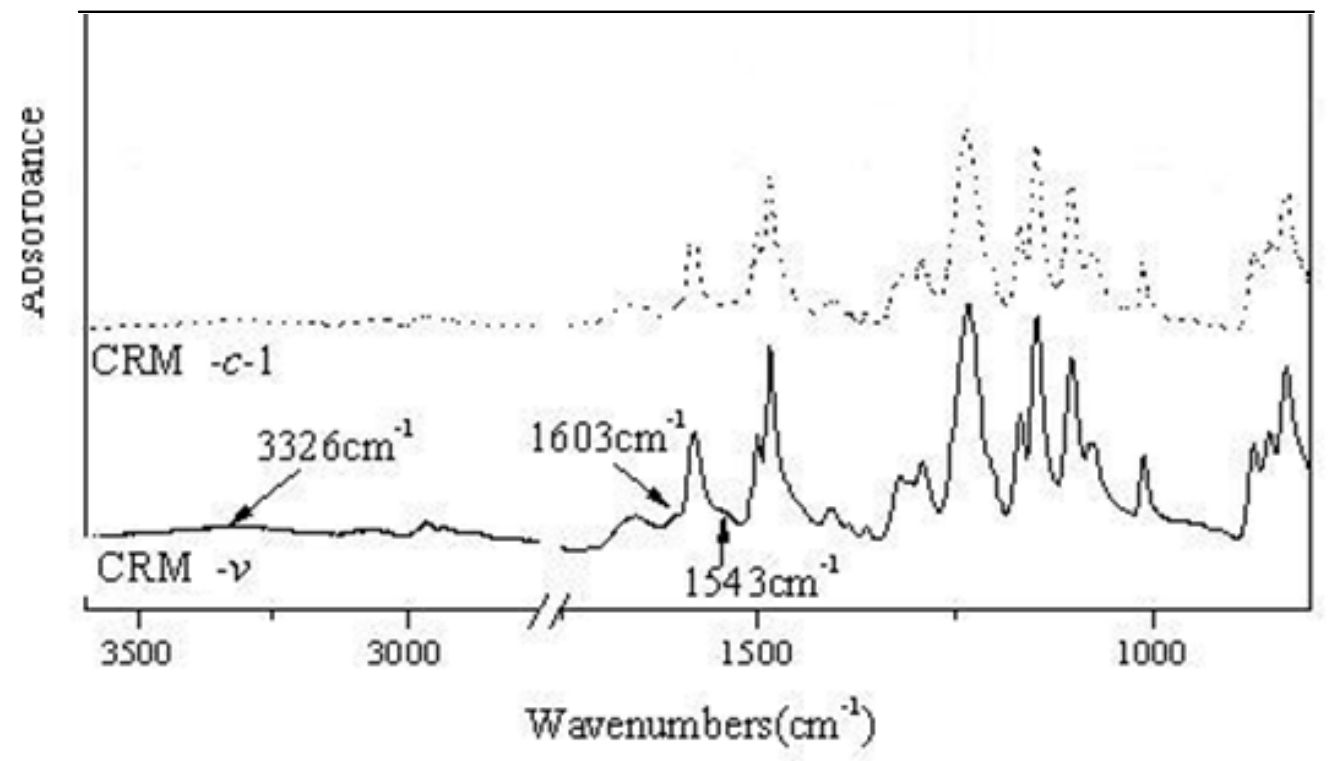

Figure 6. ATR-FTIR of virgin (lower spectrum) and chlorine damaged CRM membrane (upper spectrum).

\section{Long term chlorine resistant test using pilot system}

Fig. 7 shows a long term chlorine resistant test on BE and CRM membranes in a pilot system employing 4"x 40" elements. Initial salt rejection and flux of BE and CRM were 99.1\% and 30 gfd, and 99.2\% and 27 gfd, respectively at 225 psi using 2000 ppm NaCl.

The measured parameters are salt rejection and ppmhr, which is chlorine concentration (ppm) times time (hour). The ppmhr is often used to compare a chlorine resistance of one membrane with another membrane. One simple way is to select the ppmhr when salt rejection drops to about $90 \%$. The ppmhr of CRM is about 2500 at $90 \%$ salt rejection whereas that of BE is about 500. The result shows CRM is at least 5 times as chlorine-resistant as BE. Another way is to calculate the slope of the curve of Fig. 7 as shown in Table 1, though the curves are not linear.

As shown in fig. 8, the flux of BE and CRM is increased upon exposure to chlorine as a sign of membrane degradation by chlorine. The flux of BE is increased 8 fold, while that of CRM only 2 fold after being exposed to 10 ppm chlorine for 800 hours, indicating again that CRM is much more chlorine-resistant than BE. 


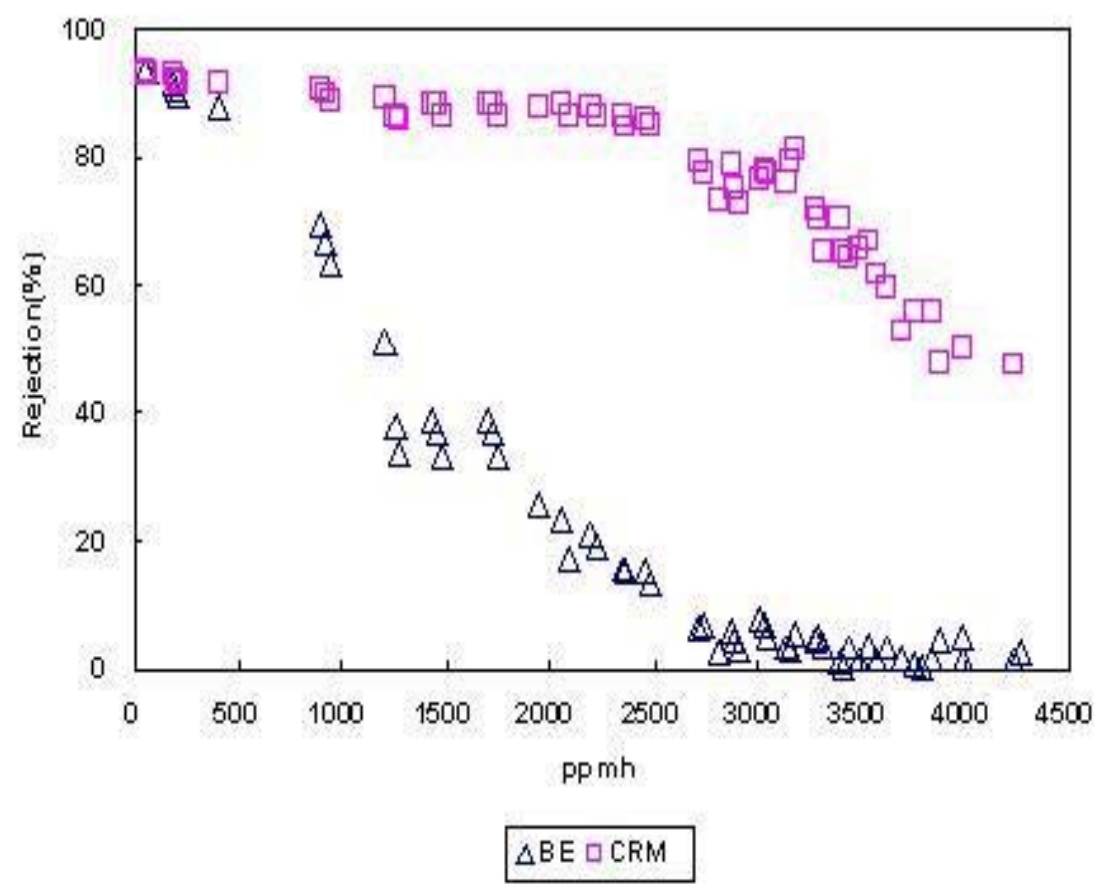

Figure 7. Chlorine resistance test of BE and CRM in a pilot system

Table 1. Comparison of Chlorine Resistance of BE to CRM

\begin{tabular}{|c|c|c|c|c|c|c|c|}
\hline \multirow[b]{2}{*}{$\begin{array}{r}\text { Chlorine } \\
\text { Contact } \\
\text { (ppm-h) }\end{array}$} & \multicolumn{3}{|c|}{$\begin{array}{c}\text { BE } \\
\text { Regular membrane } \\
\end{array}$} & \multicolumn{3}{|c|}{$\begin{array}{c}\text { CRM } \\
\text { Chlorine resistant membrane }\end{array}$} & \multirow[b]{2}{*}{$\begin{array}{c}\text { Ratio of } \\
\text { Slope } \\
\text { Rt } g E \\
R t_{C R M}\end{array}$} \\
\hline & $\begin{array}{c}\begin{array}{c}\text { Initial } \\
\text { Reiection }\end{array} \\
R_{i}\end{array}$ & $\begin{array}{c}\text { Final } \\
\text { Reiection } \\
R_{f}\end{array}$ & $\begin{array}{l}\text { Slope } \\
R_{i}-R_{f} \\
\text { ppm-h } \\
\end{array}$ & $\begin{array}{c}\begin{array}{c}\text { Initial } \\
\text { Reiection }\end{array} \\
R_{i}\end{array}$ & $\begin{array}{c}\text { Final } \\
\text { Reiection } \\
R_{f}\end{array}$ & $\begin{array}{l}\text { Slope } \\
R_{i}-R_{f} \\
\text { ppm-h } \\
\end{array}$ & \\
\hline 1000 & \multirow{3}{*}{93.43} & 63.52 & 0.029 & \multirow{3}{*}{93.23} & 88.82 & 0.0044 & 6.77 \\
\hline 2000 & & 25.67 & 0.033 & & 87.76 & 0.0027 & 12.37 \\
\hline 3000 & & 6.51 & 0.028 & & 76.50 & 0.0055 & 5.19 \\
\hline
\end{tabular}

$\mathbf{R}_{\mathbf{t}}=\mathbf{R i}-\mathbf{R}_{\mathbf{f}} / \mathbf{p p m}-\mathbf{h}$ 


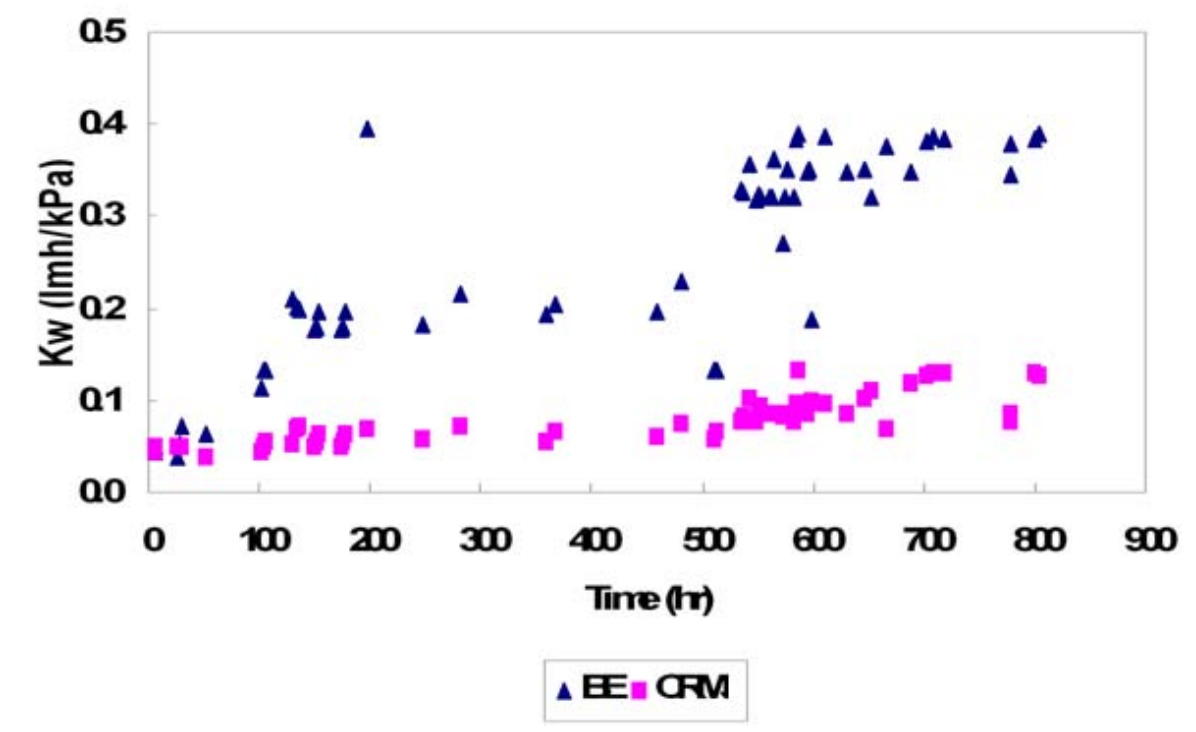

Figure 8. Specific flux (Kw) of BE and CRM upon exposure to chlorine.

\section{Effect of Monochloramine on Polyamide membrane}

The salt rejection and flux of both BE and CRM did not change after the membranes were exposed to a feed water composed of $10 \mathrm{ppm}$ monochloramine and $2 \mathrm{ppm}$ ferric chloride at pH 7 for 1000 hours.

\section{DISCUSSION}

XPS study on BE and CRM membranes exposed to chlorine reveals the presence of new peaks at $200 \mathrm{eV}$ and $270 \mathrm{eV}$ due to chlorine atom in addition to oxygen, nitrogen and carbon as shown in Figures 1 and 2, indicating chlorine atom is attached to the polyamide membranes. One noticeable difference is that the intensity of chlorine peak of Fig. 1 (BE) is greater than that of Fig. 2 (CRM), suggesting that CRM is more chlorine-resistant (less reacting with chlorine) than $\mathrm{BE}$. The difference in reactivity toward chlorine between $\mathrm{BE}$ and CRM is more graphically shown in Fig. 3, where a ratio of chlorine atom concentration to nitrogen atom concentration on BE and CRM membranes is depicted. The more is chlorine attached to the membranes, the higher is the ratio. The value of the ratio for CRM is less than half of that for $\mathrm{BE}$, indicating again that $\mathrm{BE}$ is more reactive toward chlorine than CRM. The data in Fig. 3 also tells us a majority of chlorination is done in one day exposure to chlorine. Additional 13 days exposure only resulted in extra chlorination one third of the original chlorination (BE) and one fourth (CRM). 
The effect of $\mathrm{pH}$ on chlorination of BE membrane is illustrated in Fig. 4 after being exposed to $1000 \mathrm{ppm}$ chlorine at $\mathrm{pH} 4$ for $10 \mathrm{~min}$. and at $\mathrm{pH} 10$ for $1200 \mathrm{~min}$., respectively. The intensity of chlorine peak from chlorination at $\mathrm{pH} 4$ for 10 min is greater than $\mathrm{pH} 10$ for 1200 min., suggesting chlorination rate at $\mathrm{pH} 4$ is approximately120 times as fast as $\mathrm{pH} 10$. This finding is in line with the concentration of $\mathrm{HOCl}$ depending on $\mathrm{pH}$. At $\mathrm{pH} 4$, more than $99.5 \%$ of chlorine exists as $\mathrm{HOCl}$. At $\mathrm{pH} 10$, more than $99.5 \%$ of chlorine is ionized to become $\mathrm{OCl}^{-}$and only less than $0.5 \%$ exists as HOCL (Jenkins and Snoeyink, 1980), HOCl is known to be 100 times as reactive as $\mathrm{OCl}^{-}$.

ATR-FTIR analysis of both BE and CRM before and after exposure to chlorine shows N-H stretching peak (3326 cm-1) and N-H bending peak (amide II peak) $\left(1543 \mathrm{~cm}^{-1}\right)$ disappear as shown in Fig. 5 and 6, respectively, proving that chlorine reacts with the amide hydrogen to generate $\mathrm{CON}-\mathrm{Cl}$ groups. Another interesting point is that a small peak at $1603 \mathrm{~cm}^{-1}$ due to an aromatic stretching disappears (this aromatic group is believed to belong to polyamide and the adjacent big peak belongs to polysulfone used as a support for the polyamide). This finding allows us to surmise that $\mathrm{CON}-\mathrm{Cl}$ groups may affect the adjacent aromatic ring or the chlorine atom of $\mathrm{CON}-\mathrm{Cl}$ rearranges itself to the adjacent aromatic ring (most likely MPD ring), known as Orton Rearrangement (Orton, 1928) as shown in the following diagram.

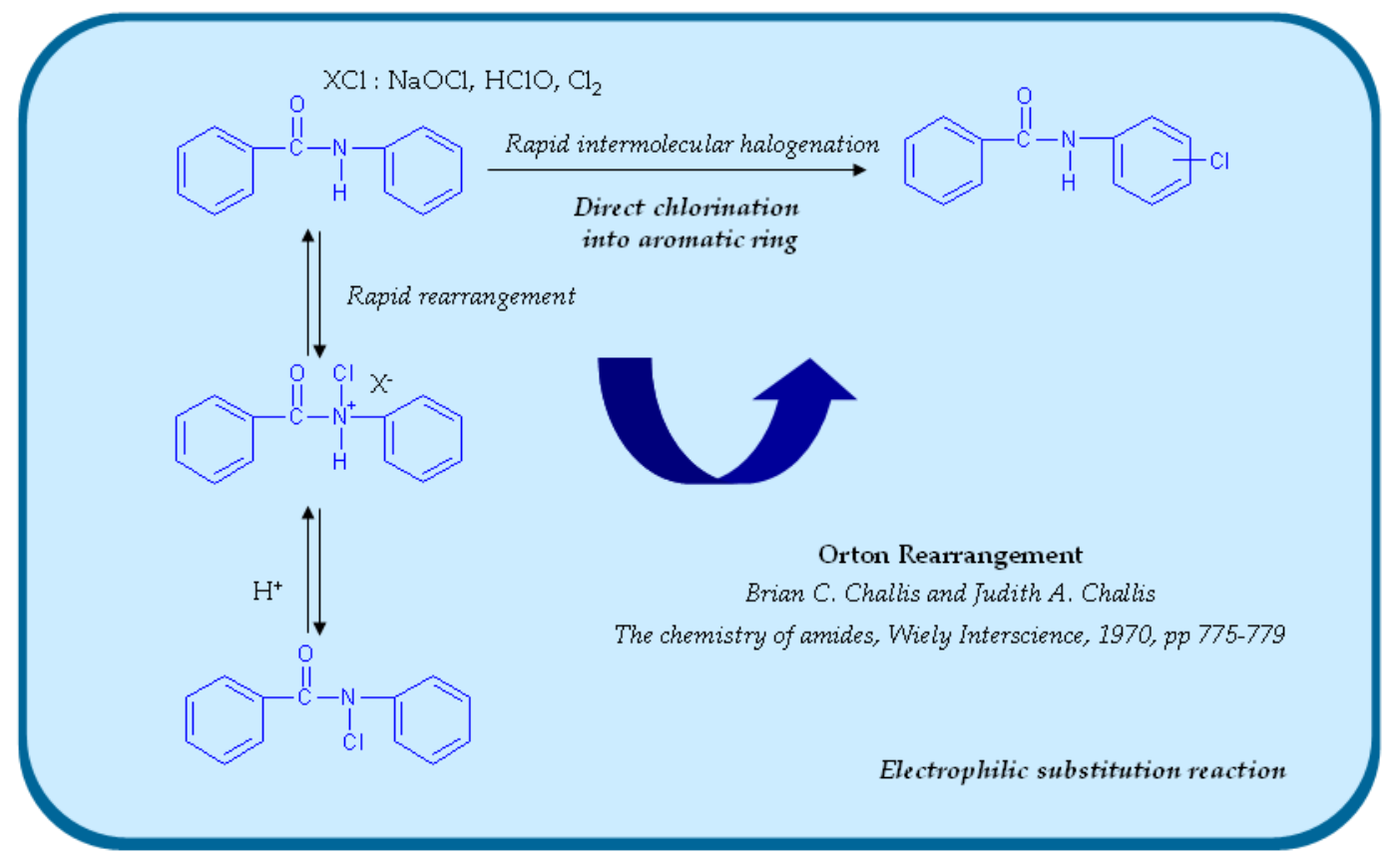

However, the possibility of direct aromatic ring chlorination cannot be ruled out completely. 
The long term chlorine resistant test of BE and CRM membranes in a pilot system shown in Fig. 7 demonstrates that CRM is at least 5 times as chlorine-resistant as BE. The difference in chlorine resistance between $\mathrm{BE}$ and CRM could arise from the fact that MPD moiety of BE undergoes chlorination directly or indirectly as described above. The amide bond of the chlorinated MPD group may be more easily hydrolyzed than the virgin amide bond. In another aspect, the chlorinated MPD moiety may be converted to a quinoid derivative upon further chlorination. The quinoid derivative can be easily hydrolyzed to result in cleavage of the polyamide chain (Koo, 1986). Subsequently, the salt rejection of the membrane decreases and the flux increases. The literatures also suggest non-MPD amines for chlorine-resistant membranes (Kawaguchi, 1984, Glater, 1994 and Shintani, 2007). In this regard, a chlorineresistant CRM membrane has been developed using a non-MPD amine.

On the contrary to chlorine, monochloramine has been found to cause no effect on the salt rejection and the flux of both $\mathrm{BE}$ and CRM, after being exposed to a feed water containing 10 ppm monochloramine and 2 ppm ferric chloride at pH 7 for 1000 hours. The literatures confirm that monochloramine itself does not harm MPD-based polyamide membranes, but in the presence of aluminum and ferric ions, monochloramine is reported to affect adversely the MPD-based polyamide membranes (Gabelich, 2002 and 2005). It is also reported that ferrous ion can react with monochloramine $\left(\mathrm{NH}_{2} \mathrm{Cl}\right)$ to generate amine radical $\left(\mathrm{NH}_{2}{ }^{\circ}\right)$, which may be responsible for attacking polyamide membrane (Vikesland, 2002) in a chain reaction as shown in the equation below.

$\mathrm{Fe}(\mathrm{II})+\mathrm{NH}_{2} \mathrm{Cl} \longrightarrow \mathrm{Fe}(\mathrm{III})+\mathrm{NH}_{2} \cdot+\mathrm{Cl}^{-}$

The literatures suggest that monochloramine can become reactive toward polyamide membranes in a right environment such as the presence of a reducing agents like ferrous ion or colloidal metal aggregates of aluminum and ferric ion. A further study is warranted to clarify this issue.

\section{CONCLUSION}

XPS analysis of a polyamide reverse osmosis membrane (BE) exposed to chlorine showed the presence of chlorine atom attached to the membrane. XPS study also showed non-MPD based chorine-resistant polyamide membrane (CRM) picked up chlorine less than half of chlorine contents of BE. ATR-FTIR analysis of the chlorine-damaged BE and CRM showed chlorine reacted with the amide hydrogen to produce $\mathrm{CON}-\mathrm{Cl}$. The chlorine atom of $\mathrm{CON}-\mathrm{Cl}$ group rearranged itself to MPD ring. It could be directly chlorinated too. A long term chlorine

resistant test on BE and CRM membranes in a pilot system for 450 hours in the presence of 
10 ppm chlorine at pH 7 reveals that CRM is at least 5 times as chlorine-resistant as BE. This may not be sufficient to give 3 years warranty in a continuous use with a feed water having 1 ppm residual chlorine. More study is required to improve the chlorine resistance of CRM. Monochloramine does not seem to affect the polyamide membranes even in the presence of ferric ion, in contradiction to the results in the literatures. A further study seems to be necessary to clarify this issue.

\section{REFERENCES}

Cadotte, J. (1981) Cross-linked polyamide reverse osmosis membrane. U.S. Pat. No. $4,277,344$

Glater, J., Hong, S.K., and Elimelech, M. (1994) The search for a chlorine-resistant reverse osmosis membrane. Desalination, 95, 325-345.

Gabelich, C.J., Yun, T.I., Coffey, B.M., and Suffet, I.H.M. (2002) Effects of aluminum sulfate and ferric chloride coagulant residuals on polyamide membrane performance. Desalination, 150, 15-30.

Gabelich, C.J., Frankin, J.C., Gerringer, F.W., Ishida, K.P., and Suffet, I.H.M. (2005) Enhanced oxidation of polyamide membranes using monochloramine and ferrous ion. J. Mem. Sci., 258, 64-70.

Jenkins, D. and Snoeyink V. L. (1980) Water Chemistry, p388 (John Wiley \& Sons Inc).

Kawaguchi, T., Tamura, H. (1984) Chlorine-resistant membrane for reverse osmosis. J. Appl. Polym. Sci. 29, 3359-3367.

Koo, J-Y., Petersen, R. J., and Cadotte, J. E. (1986) ESCA study on chlorine degradation of FT30 membrane ACS Polym. Prepr. 27(2), 391-392.

Orton, K. J. P., Soper, F. G., and Williams, G.. (1928) Intramolecular rearrangement of halogen atoms. J. Chem. Soc., 998-1005.

Shintani, T.; Matsuyama, H.; Kurata, N. (2007) Development of a chlorine-resistant polyamide reverse osmosis membrane. Desalination, 207, 340-348.

Vikesland, P.J. and Valentine, R.L. (2002) Modeling the kinetics of ferrous ion oxidation by monochloramine. Environ. Sci. Technol., 36, 662-668 